\title{
Prevention of the renarrowing of coronary arteries using drug-eluting stents in the perioperative period: an update
}

This article was published in the following Dove Press journal:

Vascular Health and Risk Management

28 September 2010

Number of times this article has been viewed

Juan V Llau'

Raquel Ferrandis'

Pilar Sierra ${ }^{2}$

Aurelio Gómez-Luque ${ }^{3}$

'Department of Anaesthesiology and Critical Care Medicine, Hospital

Clínic Universitari, València, Spain;

${ }^{2}$ Department of Anaesthesiology,

Fundació Puigvert, Barcelona, Spain;

${ }^{3}$ Department of Anaesthesiology

and Critical Care Medicine, Hospital

Clínico Universitario, Málaga, Spain
Correspondence: Juan V Llau

Department of Anaesthesiology and Critical Care Medicine, Hospital Clinic Universitari de Valencia, Avda. Blasco Ibañez 17.460I 0-Valencia-Spain Email juanvllau@gmail.com

\begin{abstract}
The management of patients scheduled for surgery with a coronary stent, and receiving 1 or more antiplatelet drugs, has many controversies. The premature discontinuation of antiplatelet drugs substantially increases the risk of stent thrombosis (ST), myocardial infarction, and cardiac death, and surgery under an altered platelet function could also lead to an increased risk of bleeding in the perioperative period. Because of the conflict in the recommendations, this article reviews the current antiplatelet protocols after positioning a coronary stent, the evidence of increased risk of ST associated with the withdrawal of antiplatelet drugs and increased bleeding risk associated with its maintenance, the different perioperative antiplatelet protocols when patients are scheduled for surgery or need an urgent operation, and the therapeutic options if excessive bleeding occurs.
\end{abstract}

Keywords: stent thrombosis, antiplatelet agents, aspirin, clopidogrel, surgical bleeding, perioperative management

\section{Introduction}

Percutaneous coronary interventions (PCIs) and coronary stent placement are now frequently and increasingly used. Among coronary stents, drug-eluting stents (DESs) seem to have some advantages over bare-metal stents (BMSs), but they need more time for complete endothelialization. ${ }^{1-3}$ As antiplatelet therapy is a key part of the management of all these patients, during the perioperative period, its management is one of the most important safety issues and, nowadays, has many controversies. ${ }^{4}$

First, the withdrawal of antiplatelet agents (APAs) seems to be associated with an increased risk of perioperative stent thrombosis (ST), myocardial infarction (MI), and death. ${ }^{5,6}$ Second, surgery under an altered platelet function could lead to an increased risk of bleeding, outweighing the benefit of continuous antiaggregation in some procedures, mainly those performed in a closed space.,

Because of the conflict in the recommendations, this article reviews the protocols of administration of APAs after the performance of a PCI with a DES placement and their management in patients scheduled for elective surgery or need an emergency intervention.

\section{Antiplatelet agents}

The most commonly used antiplatelet drugs are cyclooxygenase (COX) inhibitors, such as aspirin; adenosine diphosphate (ADP) receptor P2Y12 antagonist, such as clopidogrel, ticlopidine, prasugrel; and integrin $\alpha \mathrm{IIb} \beta 3$ (glycoprotein IIb/IIIa [GPIIb/IIIa]) receptor antagonists. ${ }^{9,10}$ 


\section{Aspirin}

The prostanoid $\mathrm{TXA}_{2}$ is the main inductor of platelet aggregation and vasoconstriction. That is, the vascular prostanoid $\mathrm{PGI}_{2}$ is the main platelet aggregation inhibitor and induces an intense vasodilatation effect. The antiplatelet action of aspirin includes the selective blocking of the platelet $\mathrm{TXA}_{2}$ synthesis by the irreversible acetylation of the enzyme COX-1, whereas COX-2-mediated $\mathrm{PGI}_{2}$ production is largely insensitive to low-dose aspirin inhibition. ${ }^{11}$ The main pharmacokinetic characteristics of aspirin are known for a long time. Aspirin, the regular uncoated tablet, is rapidly absorbed in the stomach and upper intestine, reaching peak plasma levels at 30-40 minutes after ingestion (oral bioavailability $40 \%-50 \%$ ). Enteric-coated aspirin can take up to 3-4 hours to reach peak plasma levels after its administration ${ }^{12}$ although the half-life of aspirin is close to 15-20 minutes because of its rapid clearance from the circulation. The mean life span of human platelets is approximately $8-10$ days due to both platelet and megakaryocytes COX-1 inhibition by aspirin. However, as about $10 \%-12 \%$ of circulating platelets are replaced every 24 hours, complete recovery of platelet aggregation may occur in $50 \%$ of cases by day 3 and in $80 \%$ of cases by day $4 .{ }^{13}$ The efficacy and safety of low-dose aspirin are well documented. Aspirin reduces the risks of stroke and composite outcome of stroke or death in patients with prior stroke or transient ischemic attack. ${ }^{14}$ Low doses of aspirin decrease the risk of acute MI or death in patients with both unstable angina and chronic stable angina, reduce stroke or death in patients with transient cerebral ischemia, ${ }^{15-17}$ prevent thrombotic complications in patients with polycythemia vera, ${ }^{18}$ and reduce early occlusion after aortocoronary bypass surgery ${ }^{19}$ and carotid endarterectomy. ${ }^{20}$

The balance between preventing vascular occlusion and causing excess bleeding with aspirin depends critically on the absolute thrombotic vs hemorrhagic risk of the patient. ${ }^{9}$ The meta-analyses by Antithrombotic Trialists' Collaboration about the effects of antiplatelet therapy among patients at high risk of occlusive vascular disease ${ }^{17}$ have shown that the benefits of aspirin far exceed the bleeding risks. However, it is known that some patients under aspirin therapy at usual doses (75-150 mg aspirin daily) still fail to have an optimal inhibition of thromboxane A2 pathway. These patients with such "aspirin resistance" could remain at high thrombotic risk with important clinical implications. There is a lack of uniformly accepted definition, ${ }^{21}$ and the exact prevalence is unknown but has been suggested to be between $5.5 \%$ and $60 \%{ }^{22}$ This phenomenon is important because in patients with some comorbidities, such as diabetes mellitus, hypertension, heart failure, inflammatory disorders, which may enhance aspirin resistance, the combination therapy, rather than aspirin-alone therapy, will be necessary to reach optimal antiplatelet inhibition. ${ }^{22}$

\section{ADP receptor antagonists}

The ADP P2Y12 receptor plays a central role in the formation and stabilization of thrombus and is also essential in the complete activation of GPIIb/IIIa. Clopidogrel, ticlopidine, and prasugrel act as APAs by irreversibly binding to the ADP P2Y12 receptor on platelets, subsequently preventing ADP-associated platelet aggregation. ${ }^{23}$

\section{Clopidogrel}

Clopidogrel is a parent drug. After oral administration, clopidogrel needs to be metabolized in the liver through a cytochrome P450 (CYP3A4) to active metabolite SR $26334 .^{24}$ Its plasma elimination half-life is approximately 8 hours. Clopidogrel produces detectable inhibition of platelet aggregation 2 hours after the administration of 400-600 mg oral doses, and as in the case of aspirin, platelet function returns to normal about 7 days after the last dose of clopidogrel. The benefits of clopidogrel for patients with an increased risk of recurrent ischemic events, ${ }^{17,25}$ stroke, ${ }^{26}$ and acute coronary syndromes (ACS) ${ }^{27}$ have been established by large, well-conducted randomized clinical trials. As aspirin and clopidogrel have different and complementary mechanisms of action, the combination therapy (dual antiplatelet therapy [DAT]) is more effective in preventing ST and in those presenting with ACS, compared with antiplatelet monotherapy. ${ }^{28,29}$ The American College of Cardiology/ American Heart Association (ACC/AHA) and the European Society of Cardiology (ESC) have published guidelines for the use of APAs in patients who undergo PCI ${ }^{30,31} \mathrm{~A}$ current antiplatelet protocol in patients with DESs is discussed in a separate section of this article. DAT has been associated with significantly increased risk for major bleeding in studies of more than 1 month duration compared with antiplatelet monotherapy. ${ }^{28}$ Infrequent complications include intracranial hemorrhage $(0.4 \%)$ and severe neutropenia $(0.5 \%){ }^{26}$

\section{Prasugrel}

Prasugrel is the most recently marketed oral thienopyridine derivative. The main advantages of prasugrel are that it has a faster onset of action (30 minutes) than clopidogrel, and it is a more potent $\mathrm{P} 2 \mathrm{Y} 12$ receptor antagonist, leading to higher effects of inhibition of platelet aggregation, lesser variability of response, and a lower incidence of drug resistance than 
clopidogrel. ${ }^{32}$ Prasugrel is indicated for the prevention of atherothrombotic events in patients with ACS undergoing PCI. ${ }^{33}$ In the analysis of the recent TRial to assess Improvement in Therapeutic Outcomes by optimizing platelet inhibitioN with prasugrel - Thrombolysis In Myocardial Infarction 38 (TRITON-TIMI 38) designed to compare clopidogrel with prasugrel in patients undergoing PCI, the benefit from the intensive platelet inhibitory effects associated with prasugrel was more pronounced in patients with high risk (patients with ST segment elevation MI (STEMI) and those with diabetes). ${ }^{34,35}$ However, this reduction in thrombotic events was associated with a significant increase in the risk of bleeding, which overcame the benefit of prasugrel in certain groups.

\section{Integrin $\alpha$ llb $\beta 3$ (GPIlb/Illa) receptor antagonists: abciximab, tirofiban, and eptifibatide}

After recognizing that the interaction between fibrinogen and GPIIb/IIIa is the major final step in platelet aggregation, this GP became the target of novel antiplatelet drugs, ie, the GPIIb/IIIa antagonists, such as abciximab, tirofiban, and eptifibatide. These drugs can be used alone or in combination with clopidogrel. ${ }^{36}$

\section{Abciximab}

Abciximab is a chimeric Fab fragment of the murine antihuman GPIIb/IIIa. It blocks fibrinogen ligand binding to GPIIb/IIIa. After an intravenous (IV) bolus administration, its half-life is $<30$ minutes. Abciximab $(0.25 \mathrm{mg} / \mathrm{kg}$ IV bolus dose and $0.125 \mu \mathrm{g} / \mathrm{kg} / \mathrm{min}$ infusion) produces a rapid inhibition of ADP-induced platelet aggregation with peak effects 2 hours after bolus administration. After stopping infusion, a gradual recovery of platelet function is observed and then returns to $>50 \%$ of baseline in most patients within the first 24 hours, and nearly in all patients within the first 48 hours. ${ }^{37}$ Abciximab is recommended as adjunct therapy in PCI. A meta-analysis of the 3 major clinical trials ${ }^{38-40}$ on the use of abciximab in patients undergoing PCI showed that abciximab treatment reduced the incidence of ischemic events and all-cause mortality. ${ }^{41}$ Bleeding and thrombocytopenia were the 2 most important adverse reactions associated with abciximab. Approximately $1 \%-2 \%$ of patients treated with abciximab have platelet counts $<50,000 / \mathrm{L}$, but in almost all cases, the thrombocytopenia was effectively controlled by stopping the drug administration. ${ }^{42}$

\section{Tirofiban}

Tirofiban is a specific nonpeptide antagonist of GPIIb/IIIa receptors derived from tyrosine. Bolus doses of $15 \mu \mathrm{g} / \mathrm{kg}$ followed by tirofiban infusions $0.15 \mu \mathrm{g} / \mathrm{kg} / \mathrm{min}$ produced both an inhibition of platelet aggregation induced by ADP nearly $100 \%$ and an increase of the bleeding time $>30$ minutes. Recovery of platelet function was achieved $>50 \%$ within 4 hours after discontinuing drug infusion. ${ }^{43}$ Tirofiban is effective in patients with unstable angina and non-Q-wave $\mathrm{MI}^{44}$ and protects patients undergoing coronary angioplasty for ACS. ${ }^{45}$

\section{Eptifibatide}

Eptifibatide is a synthetic heptapeptide with high selectivity by GPIIb/IIIa receptor inhibition. Bolus dose of $180 \mu \mathrm{g} / \mathrm{kg}$ of eptifibatide followed by $1 \mu \mathrm{g} / \mathrm{kg} / \mathrm{min}$ infusion decreases platelet-induced ATP aggregation $>95 \%$ and increases bleeding time to 22 minutes when compared with control values of 7-8 minutes. After stopping eptifibatide infusion, platelet function recovers $>50 \%$ of baseline aggregation within the first 4 hours. ${ }^{46}$ Eptifibatide reduces the acute adverse outcome of patients undergoing PCI, ${ }^{47}$ and it is also beneficial in patients with unstable angina. ${ }^{48}$ However, a significant interindividual variation in the inhibitory responses to eptifibatide has been reported. ${ }^{47}$

\section{Monitoring antiplatelet effect}

Tests of platelet function attempt to measure the point in the activation process reached by the platelets of an individual patient. Possible reasons for measuring platelet function in patients include screening, diagnosis, monitoring antiplatelet therapy, monitoring prohemostatic therapy, predicting thrombosis, predicting bleeding, and assessing stored platelets. ${ }^{49}$ In the perioperative period, it would be helpful to identify patients who are at risk of bleeding because of platelet dysfunction related to the administration of any APA. However, none of these tests has been validated for routine clinical practice and for monitoring antiplatelet efficiency in perioperative period of coronary interventions; the reason could be a lack of standardization, poor correlation between various tests, and expensiveness of some of them. ${ }^{50}$

A wide variety of tests are available for the measurement of platelet function, and each has its advantages and disadvantages. The tests available for assessing platelet function can be summarized as follows (Table 1): ${ }^{49,51}$

- Turbidimetric platelet aggregometry could be considered the reference assay to diagnose platelet disorders. However, it needs a platelet-rich, high-volume plasma sample; the results are not completely standardized; the laboratory procedure is complex; and the test is time consuming. 
Table I Main platelet function test for monitoring aspirin/clopidogrel therapy

Platelet function test for monitoring aspirin

Platelet function test for monitoring clopidogrel

Platelet function test for monitoring GP Ilb/IIla antagonists
Serum thromboxane B2; urinary II-dehydro

thromboxane B2; platelet aggregometry

(turbidimetric); platelet aggregometry

(impedance); VerifyNow aspirin assay;

Plateletworks; TEG platelet Mapping system;

and platelet function analyzer - 100

VASP phosphorylation (flow cytometry); platelet aggregometry (turbidimetric); platelet aggregometry (impedance); VerifyNow P2YI2 assay; Plateletworks; and TEG platelet mapping system

Platelet aggregometry (turbidimetric); platelet aggregometry (impedance); VerifyNow TRAP assay; plateletwork; and platelet flow cytometry

Abbreviations: TEG, thrombelastograph; VASP, vasodilator-stimulated phosphoprotein; TRAP, thrombin receptor activating peptide.

- Impedance aggregometry is more physiological than the optical one, but it still requires a reasonably high sample volume, and this assay is also time consuming and expensive.

- The platelet function analyzer (PFA-100) explores the platelet adhesive capacity, measuring the closure time taken for a platelet plug to occlude an aperture in a membrane impregnated with collagen and epinephrine or ADP. ${ }^{52}$ Although the test has advantages such as simplicity, rapid readout, low sample volume, no requirement for sample preparation, and that aspirin and clopidogrel have been shown to prolong this closure time, there is no evident correlation between these results and an increased perioperative bleeding.

- The Plateletworks analyzer measures the percentage of aggregation of whole blood before and after exposure to ADP. Its results are contradictory when compared with optical aggregometry: there is good correlation for clopidogrel ${ }^{53}$ but limited usage for aspirin. ${ }^{54}$ Then, it needs further studies.

- Thromboelastography is a whole blood coagulation monitor that can demonstrate the alteration of platelet aggregation. However, it is unable to detect the specific defects that occur with the administration of aspirin or clopidogrel.

- The Ultegra rapid platelet function assay system (known as VerifyNow ${ }^{\circledR}$ ) is a whole blood, point-of-care assay that incorporates a single-use cartridge with some biochemical reagents that can detect platelet dysfunction. ${ }^{55}$ It is a simple, true point-of-care device that does not need rapid pipetting and requires only a small sample volume. It has been proposed to monitor efficacy of aspirin and clopidogrel and to detect the aspirin-resistant population.
- Phosphorylation of vasodilator-stimulated phosphoprotein for the measurement of $\mathrm{P} 2 \mathrm{Y} 12$ antagonism is commercially available as a flow cytometry kit. It is dependent on the target of clopidogrel (P2Y12), and it needs low sample volume and whole blood assays, but the sample preparation is not easy, and it requires a flow cytometer and an experienced technician.

Unfortunately, none of these tests has good correlation with perioperative bleeding, so they could not predict the bleeding tendency in a patient under the effects of aspirin or clopidogrel. Further clinical investigations are necessary in this field.

\section{Drug-eluting stents}

BMSs have been developed to reduce the rate of restenosis after angioplasty. However, the restenosis rate remains high, existing in $>20 \%$ of cases, leading to ischemic coronary syndromes, or requiring revascularization in $>10 \%$ of cases. Although the BMS virtually eliminates the elastic recoil and premature negative remodeling, the proliferation of the endothelium is even more important and uncontrolled than with angioplasty alone. This concept was the basis for the development of DESs. By preventing neointimal hyperplasia, the DES has reduced the need for revascularization under $10 \% 0^{1,56,57}$ In brief, a DES is a metal stent, stainless steel or cobalt-chromium alloy, coated with a polymer containing a drug with antiproliferative properties. There are drugs from the limus family (sirolimus or rapamycin, everolimus, pimecrolimus, zotarolimus, biolimus, tacrolimus), paclitaxel $\left(\text { Taxol }^{\circledR}\right)^{58}($ Table 2).

During angioplasty, the atherosclerotic material and subendothelial tissue are exposed to the blood stream, initiating the process of thrombus formation and obstruction 
Table 2 Types of drug-eluting stent by composition

\begin{tabular}{|c|c|c|c|c|}
\hline Stent & Manufacturer & Platform & Drug & Polymer \\
\hline Cypher TM & Cordis, J\&J & Stainless steel, tubular & Sirolimus & Permanent \\
\hline Taxus $^{\mathrm{TM}}$ & Boston Scientific & Stainless steel, tubular & Paclitaxel & Permanent \\
\hline Endeavor $^{\mathrm{TM}}$ & Medtronic & Chrome-cobalt, multiple rings & Zotarolimus & Permanent \\
\hline Xience $V^{\mathrm{TM}}$ & Abbott & Chrome-cobalt, multiple rings & Everolimus & Permanent \\
\hline Promus ${ }^{\mathrm{TM}}$ & Boston Scientific & Chrome-cobalt, multiple rings & Everolimus & Permanente \\
\hline Costar $^{\mathrm{TM}}$ & Conor & Stainless steel, tubular & Paclitaxel & Biodegradable \\
\hline Axxion ${ }^{T M}$ & Biosensors & Stainless steel, tubular & Paclitaxel & Permanent \\
\hline Yukon $^{\mathrm{TM}}$ & Translumina & Stainless steel, tubular & Sirolimus & No polymer \\
\hline Janus $^{\mathrm{TM}}$ & Sorin & Coating carbon, tubular & Tacrolimus & No polymer \\
\hline Coroflex ${ }^{\mathrm{TM}}$ & Braun & Chrome-cobalt, tubular & Paclitaxel & Permanent \\
\hline Nobori ${ }^{\mathrm{TM}}$ & Terumo & Stainless steel, multiple rings & Biolimus & Biodegradable \\
\hline
\end{tabular}

Adapted from Sierra et $\mathrm{a}^{97}$ with permission.

of the coronary lumen. The metallic surface of the stent is an additional thrombogenic stimulus that persists until it is covered with endothelium. In the case of BMS, it is expected to be coated within 4-8 weeks, whereas in DES, the drug not only inhibits cell proliferation but also causes endothelial dysfunction and a local inflammatory reaction, impairing the normal healing process of an arterial injury; therefore, the thrombotic risk may persist even for years. ${ }^{59,60}$

\section{Current antiplatelet protocols in patients with DESs}

APA is recommended in the treatment of patients who had undergone PCI. After the combination therapy using aspirin and clopidogrel was introduced, the incidence of ST was reduced to $<1 \%$ of the patients, ${ }^{61}$ and it became unusual after the first month in BMS. However, ST may occur months to years after the implantation of DES in association with premature cessation of APA. The 2007 update of the ACC/ AHA/Society for Cardiovascular Angiography and Interventions (SCAI) 2005 guideline for the use of APA in patients who undergo PCI is summarized in Figure 1. ${ }^{62,63}$

\section{APA before or during $\mathrm{PCl}$}

- Patients who were already receiving daily long-term aspirin therapy should be given $75-325 \mathrm{mg}$ of aspirin before PCI (level of evidence: A).

- Patients who were not receiving daily long-term aspirin therapy should be given 300-325 mg of aspirin at least 2 hours (preferably 24 hours) before PCI (level of evidence: $\mathrm{C})$.

- A clopidogrel loading dose (LD), usually of $600 \mathrm{mg}$, should be administered before or during PCI (level of evidence: $\mathrm{C}$ ).
- In patients undergoing PCI after 12-24 hours of fibrinolytic therapy, a clopidogrel oral LD of $300 \mathrm{mg}$ may be considered (level of evidence: $\mathrm{C}$ ).

- If clopidogrel is given at the time of PCI, supplementation with GPIIb/IIIa receptor antagonists may be beneficial (level of evidence: B).

- In patients with absolute contraindication to aspirin, a single administration of clopidogrel both 300 and $600 \mathrm{mg}$ LD at least 6 hours before PCI, supplemented with or without GPIIb/IIIa antagonists, at the time of PCI is recommended (level of evidence: $\mathrm{C}$ ).

There is an agreement about the benefit of higher LD of clopidogrel in patients undergoing PCI. Several authors have analyzed the effects of different LDs (300 or $600 \mathrm{mg}$ ) on the inhibition of platelet aggregation, myonecrosis (troponin I release), and clinical outcomes in patients undergoing PCI. Greater dose of clopidogrel has shown an increase of antiplatelet effect and a significant decrease of major adverse cardiac events, in comparison with $300 \mathrm{mg} \mathrm{LD}$, which supports a clinical benefit of higher dose of clopidogrel in patients subjected to PCI. ${ }^{64,65}$

\section{APA after $\mathrm{PCl}$}

- In patients subjected to PCI and with no allergies or increased risk of bleeding, aspirin 162-325 mg daily should be given for at least 1 month after BMS implantation, 3 months after sirolimus-eluting stent implantation, and 6 months after paclitaxel-eluting stent implantation. Afterward, a daily dose of 75-162 mg of aspirin should be maintained indefinitely (level of evidence: B).

- The use of low-dose aspirin is supported by data from post hoc analysis of the Clopidogrel in Unstable angina to prevent Recurrent Events (CURE) study. ${ }^{66}$ No differences in 


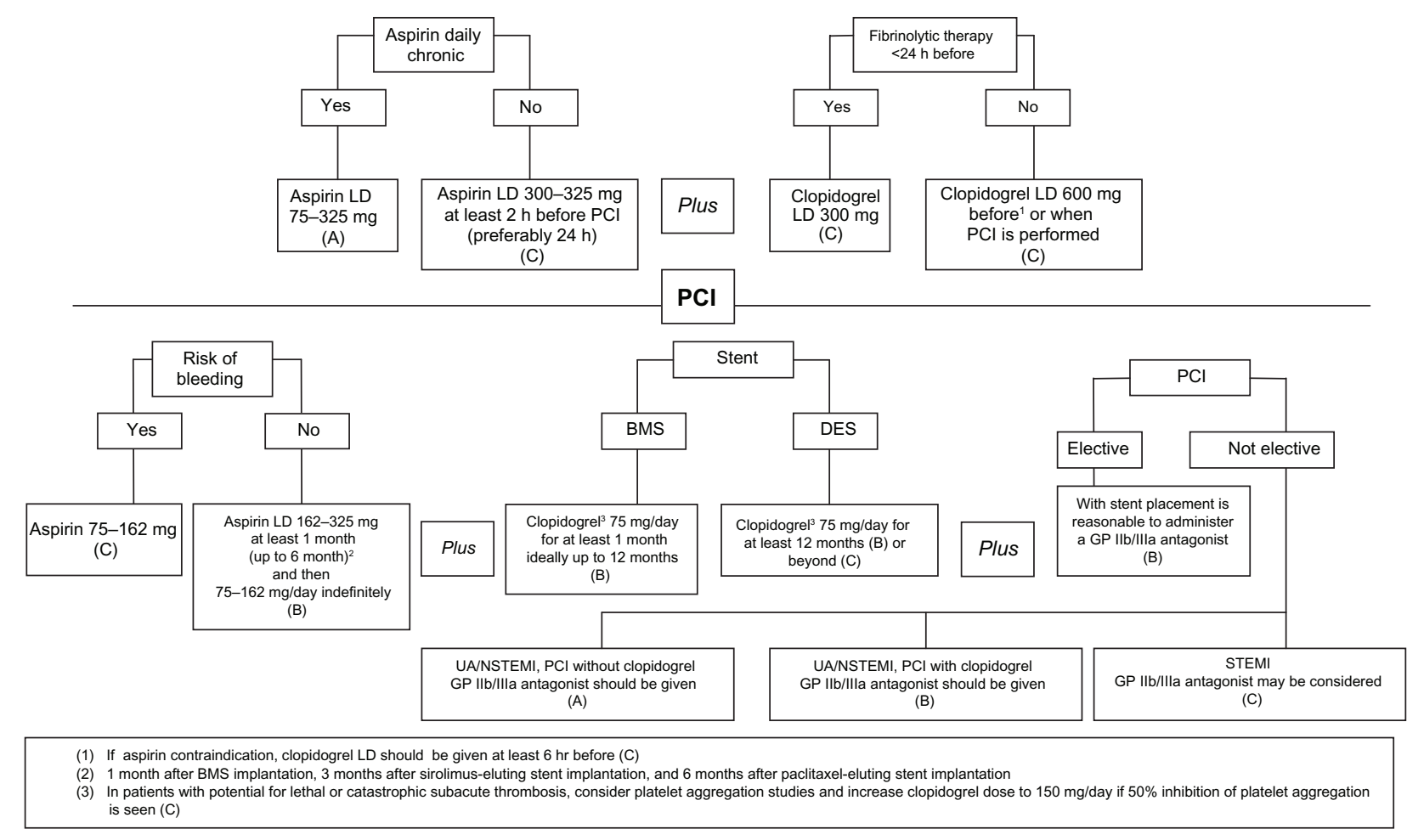

Figure I The 2007 update on the recommendations of the ACC/AHA/SCAI 2005-2007 last-updated guidelines on use of antiplatelet drugs in patients who undergo PCI. Note: In parenthesis, the level of evidence is given.

Abbreviations: PCl, percutaneous coronary intervention; LD, loading dose; BMS, bare-metal stent; DES, drug-eluting stent; UA, unstable angina; NSTEMI, non-ST segment elevation myocardial infarction; STEMI, ST segment elevation myocardial infarction.

the efficacy among the 3 aspirin dose groups ( $<100 \mathrm{mg}$, $101-199 \mathrm{mg}$, and $\geq 200 \mathrm{mg}$ ) in combination with clopidogrel have been found. However, an increase of major bleeding incidence has been reported with the highest dose of aspirin either alone or with the combination of clopidogrel. ${ }^{67}$ Therefore, these data suggest an optimal daily dosage of aspirin between 75 and $100 \mathrm{mg}$ to minimize bleeding risk (level of evidence: $\mathrm{C}$ ).

- In post-PCI patients receiving a BMS, clopidogrel should be given for a minimum of 1 month, whereas it should be given only for a minimum of weeks for patients with an increased risk of bleeding (level of evidence: B).

- In all post-PCI patients with DES and without high risk of bleeding, clopidogrel $75 \mathrm{mg}$ daily should be given for at least 12 months (level of evidence: B).

These recommendations are based on the antiplatelet regimen used in clinical trials conducted to achieve the approval of US Food and Drug Administration (low-risk lesions in lowrisk patients). The anticipated times have been taken for the predicted metal stent struts adequate endothelialization time, which reduces the ST risk efficiently. The effect of continuous use of clopidogrel in patients receiving BMS or DES at 6 and 12 months was analyzed by an observational study including
3,165 patients. Clopidogrel did not modify the incidence of death or MI at 24 months in patients with BMS. However, the continuous use of clopidogrel was associated with lower rates of death or MI in patients with DES.$^{68}$ The American Heart Association Science Advisory (AHAA) stresses the importance of 12 months DAT and provides reports about the potential hazards associated with premature discontinuation of these drugs, and thus, they recommend that the prolongation of clopidogrel therapy beyond 1 year may be considered in patients undergoing DES placement (level of evidence: $\mathrm{C}$ ).

In a recent meta-analysis, a triple therapy (aspirin plus thienopyridine plus cilostazol) has been evaluated to know the effect of adding cilostazol to a dual antiplatelet regimen to prevent stent restenosis. ${ }^{69}$ The 6-month restenosis rates are significantly lower with triple therapy vs DAT, which seems a promising way to reduce cardiac events in patients with coronary artery stent.

\section{Bleeding and thrombotic risk stratification in the perioperative period}

The perioperative management of APA must be based on the optimal assessment of benefit - risk relationship. This 
includes the stratification of the perioperative hemorrhagic risk associated with the continuation of APAs throughout surgery and the stratification of the thrombotic risk associated with the discontinuation of APA (Table 3). ${ }^{7,8,70-72}$

\section{Bleeding risk}

The perioperative risk for hemorrhage depends on the type of APA, the monotherapy or combination therapy, and the surgical procedures. As a general rule, the risk of bleeding probably increases when the patient receives a dual therapy or when antiplatelet therapy is associated with an anticoagulant drug (heparin, low-molecular-weight heparin, fondaparinux, warfarin). When aspirin is given as monotherapy, the surgical bleeding and its related complications have been calculated to increase by a factor $1.5,{ }^{73}$ but it is controversial if this result could be extended to all surgical procedures. ${ }^{72}$ Indeed, the evidence on the risk of bleeding in patients under the effect of APA is also controversial, and the results of several recent studies are not fully conclusive. ${ }^{74}$

Finally, the increased bleeding risk with aspirin does not mean necessarily an increase in mortality or morbidity, an increase in transfusion requirements, ${ }^{75}$ or a worse result in the surgical procedure, with the exception of surgery in a closed space, and possibly transurethral prostatectomy. Moreover, the risk of surgical bleeding is also increased in these patients due to DAT. Burger et $\mathrm{al}^{73}$ have demonstrated, through a metaanalysis of 41 studies involving 49,590 patients undergoing different types of noncardiac surgery, that the bleeding risk is multiplied by a factor 1.5 when aspirin treatment is continued. Yet, this is not accompanied by the increased risk of major bleeding complications, with the exception of cases in which minor bleeding may have catastrophic results, such as intracranial surgery. Also prostate surgery, transurethral resection, and radical surgery are generally considered high risk for bleeding, but in the last few years, the improved resection techniques and laparoscopic approach have helped to reduce the risk of hemorrhage in these cases. ${ }^{76}$

There are no randomized controlled studies that evaluate the risk of bleeding when continuing treatment with clopidogrel in noncardiac surgery. In some case series, the continuation of clopidogrel in the perioperative period is not associated with excessive bleeding. ${ }^{77}$ With regard to coronary bypass surgery, the CURE trial showed no major bleeding among patients who continued clopidogrel treatment up to 5 days before surgery vs patients who discontinued clopidogrel 5 days or more before surgery, without any difference in mortality. ${ }^{78}$

In conclusion, in noncardiac surgery, bleeding could be considered as a "minor" complication, and severe events are more frequently of cardiac origin.

\section{Thrombotic risk}

$\mathrm{ST}$ is a severe complication that is associated with a high incidence of acute MI (22\%-90\%) and death (30\%-45\%). ${ }^{79-81}$ The current procedure of DAT with aspirin and thienopyridine (usually clopidogrel) has reduced the incidence of ST to around $2 \%$ in the long term. ${ }^{82,83}$ According to the time elapsed since the stent implantation, ST is considered "early" in the first 30 days, "late" from 30 days to 1 year, and "very late" after 1 year. ${ }^{84}$ The first 30 days after stent placement is the period of higher risk of thrombosis, with an incidence of $60 \%-75 \%$ of cases with ST. ${ }^{82}$ Although early ST is generally considered to be related to the procedure, late and very late events are less frequent, and discontinuation of antiplatelet therapy seems to be an important risk factor. ${ }^{84}$

Nevertheless, over the past few years, some observational studies found that late and very late DES thromboses occurred more frequently than reported in previous randomized controlled trials, with an increased risk of mortality. ${ }^{85}$

Table 3 Proposed stratification of the hemorrhagic risk related with the continuation of antiplatelet agents through the perioperative period and the thrombotic risk associated with their discontinuation

\begin{tabular}{|c|c|c|}
\hline Minor & Moderate & Major \\
\hline \multicolumn{3}{|l|}{ Hemorrhagic risk } \\
\hline $\begin{array}{l}\text { Transfusion usually not needed; minor plastic/ } \\
\text { general/OS surgery; and biopsies, tooth extraction, } \\
\text { surgery of the anterior segment of eye }\end{array}$ & $\begin{array}{l}\text { Transfusion usually needed; cardiac } \\
\text { surgery; major OS/visceral/ENT/urology } \\
\text { or reconstructive surgery }\end{array}$ & $\begin{array}{l}\text { Possible bleeding in an enclosed space; cranial } \\
\text { surgery; spinal surgery; surgery of the posterior; } \\
\text { segment of eye; and transurethral prostatectomy }\end{array}$ \\
\hline \multicolumn{3}{|l|}{ Thrombotic risk } \\
\hline $\begin{array}{l}>6 \text { mo after AMI; CABG; percutaneous } \\
\text { coronariography; BM; coronary surgery; } \\
\text { and CVS (>I } 2 \text { mo if high-risk patient or } \\
\text { associated complications) }\end{array}$ & $\begin{array}{l}>12 \text { mo after DES; } 6-36 \text { wks after AMI; } \\
\text { CABG; BMS; and CVS (6-12 mo if high- } \\
\text { risk patient or associated complications) }\end{array}$ & $\begin{array}{l}<12 \text { mo after DES; }<6 \text { wks after AMI; CABG; } \\
\text { BMS; and CVS ( }<6 \text { mo if high-risk patient or } \\
\text { associated complications) }\end{array}$ \\
\hline
\end{tabular}

Abbreviations: OS, orthopedic surgery; ENT, ear-nose-throat surgery; AMI, acute myocardial infarction, CABG, coronary artery bypass grafting; BMS, bare metal stent, DES, drug-eluting stent; CVS, cerebrovascular stroke. 
It appeared to be related to the premature discontinuation of antiplatelet therapy and with the higher use of DESs in off-label indication (around 60\% of cases in real-world practice). ${ }^{86}$ Thus, the safety of DES was questioned.

Recent studies with longer follow-up period allow us to summarize the current situation. In a recent Swedish observational study of 17,198 patients followed up for 1-4 years after stent placement, no significant differences in the risk of death or MI were found between both types of stent, in the case of either on-label or off-label use. ${ }^{87}$ Lastly, Kirtane et al ${ }^{88}$ have published an extensive metaanalysis of DES vs BMS in on-label and off-label uses. They conclude that the use of DES compared with BMS is associated with a significant reduction (46\%-55\%) in target vessel revascularization. These results seem to be consistent in demonstrating that DES use is safe for a broad range of lesions and patients at various risk levels.

However, there are different time patterns for the ST depending on the type of stent. Although early thrombosis is more frequent in BMS, the incidence of late and very late thromboses is higher in DESs. ${ }^{82,89}$ Several studies have identified multiple factors that contribute to ST (Table 4). ${ }^{90}$ Some scoring systems have been recently developed to estimate the risk for ST; one of them include 8 significant predictors, with a stratification of patients in low, medium, and high risk groups, and has been validated using 1-year data from 4,820 patients (Table 5). ${ }^{91}$

Finally, it is necessary to highlight that because of its relation with perioperative period, most authors agree that premature discontinuation of DAT was strongly associated with ST ${ }^{82,90,92}$ with a higher risk if clopidogrel is discontinued during the first 6 months after stenting. At 12 months, the cessation of clopidogrel does not appear to be related with a higher risk of ST. ${ }^{93,94}$

\section{Management of APAs in the perioperative period}

Around $5 \%$ of patients with a coronary stent are scheduled for noncardiac surgery within the first year after stent implantation. ${ }^{94}$ Perioperative incidence of major adverse cardiac events and mortality in noncardiac surgery in these patients can reach a rate of $2.5 \%-21.4 \%$ in the case of ST. ${ }^{95}$ This increased risk is strongly associated with the time elapsed from stenting to surgery and the premature discontinuation of DAT. Thus, this risk could be reduced by delaying surgery until the prescribed antiplatelet regimen is completed. ${ }^{77,96}$ Abrupt cessation of antiplatelet therapy may be followed by an increase of platelet reactivity or "rebound" effect in patients on chronic antiplatelet treatment. In addition, surgery itself creates a thrombogenic situation. The endocrine response to surgical stress may indirectly contribute to adverse cardiovascular events, such as increased vascular reactivity (vasospasm), platelet activation, increased clotting factors in plasma, and decreased fibrinolysis, in the perioperative period. Then, the risk of cardiac event in the perioperative period is not entirely prevented by continued DAT.

The decision to discontinue the antiplatelet therapy before surgery should be based on careful cardiovascular and thrombotic risk assessment of the patient and on the type of surgery and bleeding risk. In patients with coronary stent, it is essential to have specific information on the characteristics of coronary disease that has led to stent implantation, the date of procedure, the type of stent implanted, and the current antiplatelet regimen. ${ }^{97}$

The recommendations about the perioperative management of antiplatelet therapy in these patients are not fully agreed, but they can be summarized as follows (Figure 2): $:^{7,8,71,96-100}$

- Whenever possible, antiplatelet therapy should be maintained during the high-risk period for as long as it is currently recommended: low-dose aspirin (75-100 mg) indefinitely, and clopidogrel $75 \mathrm{mg}$ at least during 12 months after DES placement. Therefore, if the surgery is likely to cause little or no risk of bleeding, it is recommended to continue the antiplatelet therapy. However, regarding elective procedures in which there is a significant risk of perioperative bleeding, surgery should be delayed until patients have completed the DAT.

Table 4 Risk factors of stent thrombosis

\begin{tabular}{ll}
\hline Procedure-related factors & Stent malposition; stent underexpansion; stent length; persistent slow coronary blood flow; \\
& positive remodeling; and residual arterial dissection \\
Patient and lesion-related factors & Stenting in the setting of an acute coronary syndrome; premature antiplatelet therapy \\
discontinuation; no response to aspirin and/or clopidogrel; low ejection fraction; diabetes & mellitus; advanced age; stenting: bifurcated lesions, long lesions, small vessels, complex lesions; \\
& and in-stent restenosis \\
Characteristics of stent-related factors & Delayed endothelialization; type of drug, kinetics of drug release; material and designing; \\
& polymer versus nonpolymer; type of polymer; and hypersensibility to polymer \\
\hline
\end{tabular}


Table 5 Clinical risk score for prediction of stent thrombosis and risk stratification as developed by Baran et $\mathrm{al}^{91}$

\begin{tabular}{lll}
\hline Clinical factors & Hazard ratio & Weight \\
\hline Thienopyridine discontinuation $<6$ mo & 5.28 & 5 \\
Insulin treated diabetes & 4.74 & 5 \\
Left main stenting & 2.73 & 3 \\
Smoking status & 2.63 & 3 \\
Lesion length $>28 \mathrm{~mm}$ & 2.35 & 2 \\
Multiple stenting & 2.25 & 2 \\
Moderate to severe lesion calcification & 2.25 & 2 \\
Reference vessel diameter $<3$ mm & 1.72 & 2 \\
Total possible score & & 24 \\
Risk stratification & & \\
$\quad$ Low (ST rate\%) & & $0-6(0.8)$ \\
Moderate (ST rate\%) & & $7-13(3.6)$ \\
High (ST rate\%) & & $14-24(12.6)$ \\
\hline Abreviation: ST stent thrombsis.
\end{tabular}

Abbreviation: ST, stent thrombosis.

- In all cases, it is recommended that a low-dose aspirin (75-100 mg) is maintained throughout the perioperative period, unless the risk of bleeding clearly outweighs thrombotic risk. To reduce the potential risk of bleeding, aspirin dose $>200 \mathrm{mg}$ should be replaced by 75 or $100 \mathrm{mg}$.

- The treatment should be substituted by low-dose aspirin in the case of patients treated with clopidogrel as monotherapy, and where discontinuation is mandatory (unless contraindicated).

- If antiplatelet therapy must be discontinued, it should be stopped the shortest time possible: 2 days for aspirin and 5 days for clopidogrel. Thereafter, treatment should be restarted as soon as possible following surgery after ensuring hemostasis, between 6 and 48 hours during the postoperative period. Depending on the withdrawal time and to accelerate antiplatelet response, LD administration may be indicated as follows: aspirin $250 \mathrm{mg}$, clopidogrel $300 \mathrm{mg}$.

Protocols involving the use of short-acting substances, such as IV administration unfractioned heparin and the infusion of either epifibatide or tirofiban, have been proposed to act as a bridge when the discontinuation of clopidogrel and/or aspirin is mandatory. It should be started 3 days before surgery and stopped $4-8$ hours before surgery. ${ }^{101,102}$ However, currently there is no enough evidence to recommend their use. ${ }^{71}$ Some authors defend that if aspirin is maintained, the short-term discontinuation of clopidogrel may be relatively safe without bridge therapy. ${ }^{103}$

\section{Management of the APAs in cases of emergency surgery}

In the patients under the effect of any APA and undergoing emergency surgery, the key questions are the decision on the need to prevent or to treat bleeding, minimizing the risks of ischemia and ST, and whether the hemorrhagic risk may endanger the vital or functional prognosis of the intervention. The following strategies could be considered to decrease the consequences of hemorrhage.

\section{Pharmacological treatment}

The administration of desmopressin has been suggested to reduce excessive bleeding in patients scheduled for cardiac surgery under the effects of aspirin. However, consistent beneficial effects of this practice cannot be shown in large studies, and the drug cannot be recommended for current practice as an effective hemostatic agent in patients treated with aspirin. ${ }^{104}$ The use of recombinant factor VII is controversial. It has been included "off-label" in some strategies or protocols to control a life-threatening hemorrhage because it could reverse the inhibitory effect of clopidogrel, ${ }^{105}$ but there is not enough evidence to support its inclusion as a standard recommendation in urgent surgery for patients under the effect of an APA.

\section{Platelet transfusion}

As there is no drug to directly antagonize the antiplatelet effect of aspirin or clopidogrel, sometimes, platelet transfusion (1 U/5-10 kg) may be needed to stop bleeding. ${ }^{106}$ Regular prophylactic transfusion of platelets should be discouraged and evaluated carefully on a case-by-case basis, considering the expected benefit gained from it and the possible risks of platelet transfusion. In patients who have received clopidogrel, despite the low immediate hemostatic effect, the preoperative transfusion of platelets could be a good alternative to facilitate postoperative hemostasis, only if the patients undergo surgery with high bleeding risk..$^{52,107}$

The dilemma of whether to transfuse platelets before the beginning of clinical bleeding or only with the aim of treating a clinically significant hemostatic alteration depends in most cases on the kind of surgery and if the inherent bleeding could have a bad vital or functional implication.

\section{Semiurgent surgery}

What to do if surgery cannot be delayed and the patient is in a high-risk period for thrombosis? The management of APA should have minimizing the ST risk as priority, trying to expose the patient to the minimal bleeding risk. Several protocols have been proposed with a multidisciplinary approach, although none of them has been completely validated:, ${ }^{9} 106$

- Low bleeding risk: The recommendation is to maintain dual therapy until the day before surgery. 


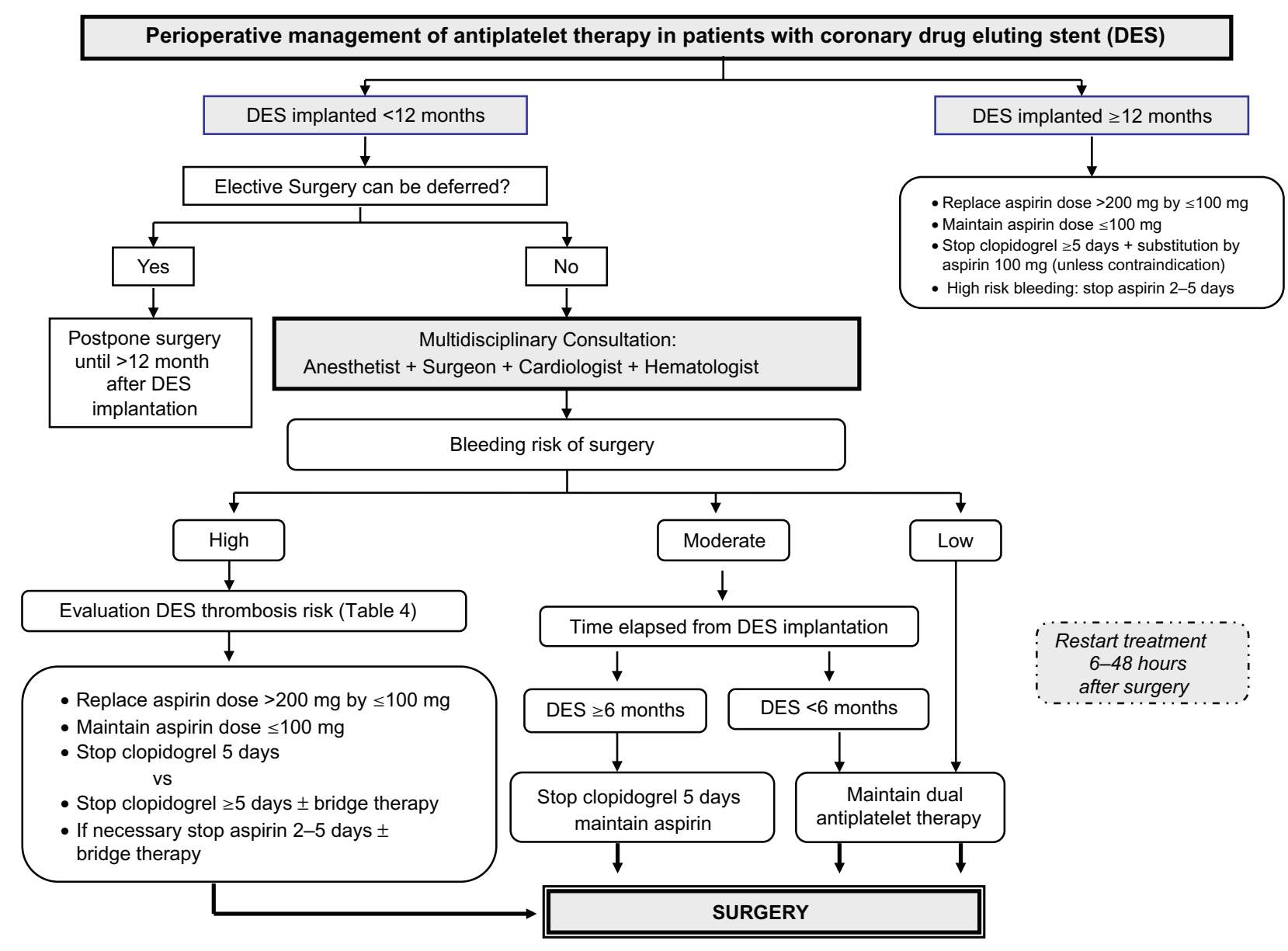

Figure 2 Perioperative management of antiplatelet therapy in patients with drug-eluting stents (DES).

- Moderate bleeding risk: Aspirin should be continued, and clopidogrel should be stopped 5 days before surgery. Some authors have proposed a bridging therapy, with the infusion of tirofiban and unfractionated heparin started 3 days before surgery and maintained until 6 hours before surgery, mainly if the patient has additional risk factors and very high thrombotic risk of DES, ${ }^{101}$ or the infusion of tirofiban only started 4 days before surgery until 4 hours before surgery. ${ }^{108}$

- High bleeding risk: Aspirin and clopidogrel should be discontinued 5 days before surgery (considered to be the best option), or aspirin and clopidogrel should be stopped 10 days before surgery and a bridging therapy should be started as explained earlier.

\section{Conclusions}

Surgery after coronary stent placement is associated with a moderate to high risk of major adverse cardiac events, mostly caused by in-stent thrombosis due to the prothrombotic and proinflammatory states, which lead to hypercoagulability associated with surgical intervention. The interruption of antiplatelet therapy before surgery and/or through the perioperative period could have a rebound effect with an increase in the hypercoagulation and prothrombotic state and more risk for ST.

On the other hand, the maintenance of APA could increase the risk of bleeding in some interventions, with a wide range of implications: from no influence in the development of surgery and outcome to a vital risk associated with bleeding in closed spaces. So, the challenge for the surgical team is to use a therapy that can minimize both thrombotic and hemorrhagic risks to reach the better benefit for the patient.

Although there is no valid algorithm for all situations, current trend is to delay all surgery that is not life-threatening if the stent has high thrombotic risk and, if not possible, to give optimal protection to the patients with BMS or DES with the maintenance of at least an APA, or running an alternative protocol with anticoagulants and aspirin. In all other patients, aspirin should be maintained throughout the perioperative period if possible, balancing individual benefit/risk ratio of the withdrawal of APA. 


\section{Disclosure}

The authors report no conflicts of interest in this work.

\section{References}

1. Newsome LT, Kutcher MA, Royster RL. Coronary artery stents, Part I: Evolution of percutaneous coronary intervention. Anesth Analg. 2008;107:552-569.

2. Sharma RK, Reddy HK, Singh VN, et al. Aspirin and clopidogrel hyporesponsiveness and nonresponsiveness in patients with coronary artery stenting. Vasc Health Risk Manag. 2009;5:965-972.

3. Gasparyan AY. Aspirin and clopidogrel resistance: methodological challenges and opportunities. Vasc Health Risk Manag. 2010;6: 109-1012.

4. Ferrandis R, Llau JV, Mugarra A. Perioperative management of antiplatelet-drugs in cardiac surgery. Curr Cardiol Rev. 2009;5: 125-132.

5. Spahn DR, Howell SJ, Delabays A, Chassot PG. Coronary stents and perioperative anti-platelet regimen: dilemma of bleeding and stent thrombosis. Br J Anaesth. 2006;96:675-677.

6. Rabbits JA, Nuttall GA, Brown MJ, et al. Cardiac risk of noncardiac surgery after percutaneous coronary intervention with drug-eluting stents. Anesthesiology. 2008;109:596-604.

7. Llau JV, López-Forte C, Sapena ML, Ferrandis R. Perioperative management of antiplatelet agents in noncardiac surgery. Eur $J$ Anaesthesiol. 2009;26:181-187.

8. Chassot PG, Delabays A, Spanh DR. Perioperative antiplatelet therapy: the case for continuing therapy in patients at risk of myocardial infarction. Br J Anaesth. 2007;99:316-328.

9. Patrono C, Baigent C, Hirsh J, Roth G. Antiplatelet drugs: American College of Chest Physicians Evidence-Based Clinical Practice Guidelines (8th edition). Chest. 2008;133 Suppl 6:199S-233S.

10. Angiolillo D, Ferreiro JL. Platelet adenosin diphosphate P2Y12 receptor antagonism: benefit and limitations of current treatment strategies and future directions. Rev Esp Cardiol. 2010;63:60-76.

11. Vane JR, Botting RM. The mechanism of action of aspirin. Thromb Res. 2003;110:255-258.

12. Cox D, Maree AO, Dooley M, Conroy R, Byrne MF, Fitzgerald DJ Effect of enteric coating on antiplatelet activity of low-dose aspirin in healthy volunteers. Stroke. 2006;37:2153-2158.

13. Jimenez AH, Stubbs ME, Tofler GH, Winther K, Williams GH, Muller JE. Rapidity and duration of platelet suppression by entericcoated aspirin in healthy young men. Am J Cardiol. 1992;69: 258-262

14. Diener HC, Cunha L, Forbes C, Sivenius J, Smets P, Lowenthal A European Stroke Prevention Study, Part II: Dipyridamole and acetylsalicylic acid in the secondary prevention of stroke. J Neurol Sci. 1996;143:1-13.

15. International Stroke Trial Collaborative Group. The International Stroke Trial (IST): a randomized trial of aspirin, subcutaneous heparin, both, or neither among 19,435 patients with acute ischemic stroke. Lancet. 1997;349(9065):1569-1581.

16. ISIS-2 Collaborative Group. Randomized trial of intravenous streptokinase, oral aspirin, both or neither among 17,187 cases of suspected acute myocardial infarction: ISIS-2. Lancet. 1988;2(8607): 349-360.

17. Antithrombotic Trialists Collaboration. Collaborative meta-analysis of randomized trials of antiplatelet therapy for prevention of death, myocardial infarction, and stroke in high-risk patients. $B M J$ 2002;324(7329):71-86.

18. Landolfi R, Marchioli R, Kutti J, et al. Efficacy and safety of low-dose aspirin in polycythemia vera. $N$ Engl J Med. 2004;350:114-124.

19. Lorenz RL, Schacky CV, Weber M, et al. Improved aortocoronary bypass patency by low-dose aspirin ( $100 \mathrm{mg}$ daily): effects on platelet aggregation and thromboxane formation. Lancet. 1984;1(8389): $1261-1264$
20. Juul-Möller S, Edvardsson N, Jahnmatz B, Rosén A, Sørensen S, Omblus R. Double-blind trial of aspirin in primary prevention of myocardial infarction in patients with stable chronic angina pectoris. Lancet. 1992;340(8833):1421-1425.

21. Gasparyan AY, Watson T, Lip GY. The role of aspirin in cardiovascular prevention: implications of aspirin resistance. J Am Coll Cardiol. 2008;51:1829-1843.

22. Bonvini RF, Reny JL, Mach F, et al. Acute coronary syndrome and its antithrombotic treatment: focus on aspirin and clopidogrel resistance. Curr Vasc Pharmacol. 2009;7:198-208.

23. Gachet $\mathrm{C}$. The platelet $\mathrm{P} 2$ receptors as molecular targets for old and new antiplatelet drugs. Pharmacol Ther. 2005;108:180-192.

24. Boeynaems JM, van Giezen H, Savi P, Herbert JM. P2Y12 receptor antagonists in thrombosis. Curr Opin Investig Drugs. 2005;6: 275-282.

25. CAPRIE Steering Committee. A randomized, blinded, trial of clopidogrel versus aspirin in patients at risk of ischemic events (CAPRIE). Lancet. 1996;348(9038):1329-1339.

26. Sudlow CL, Mason G, Maurice JB, Wedderburn CJ, Hankey GJ. Thienopyridine derivatives versus aspirin for preventing stroke and other serious vascular events in high vascular risk patients. Cochrane Database Syst Rev. 2009;(4):CD001246.

27. Mehta SR, Yusuf S; Clopidogrel in Unstable angina to prevent Recurrent Events (CURE) Study Investigators. The Clopidogrel in Unstable angina to prevent Recurrent Events (CURE) trial programme; rationale, design and baseline characteristics including a meta-analysis of the effects of thienopyridines in vascular disease. Eur Heart J. 2000;21:2033-2041.

28. Bowry AD, Brookhart MA, Choudhry NK. Meta-analysis of the efficacy and safety of clopidogrel plus aspirin as compared to antiplatelet monotherapy for the prevention of vascular events. Am J Cardiol. 2008;101:960-966.

29. De Luca G, Cassetti E, Marino P. Impact of duration of clopidogrel prescription on outcome of DES as compared to BMS in primary angioplasty: a meta-regression analysis of randomized trials. JThromb Thrombolysis. 2009;27:365-378.

30. Antman EM, Anbe DT, Armstrong PW, et al. ACC/AHA guidelines for the management of patients with ST-elevation myocardial infarction. J Am Coll Cardiol. 2004;44:671-719.

31. Silber S, Albertsson P, Avilés FF, et al. Guidelines for percutaneous coronary interventions. Eur Heart J. 2005;26:804-847.

32. Duggan ST, Keating GM. Prasugrel: a review of its use in patients with acute coronary syndromes undergoing percutaneous coronary intervention. Drugs. 2009;69:1707-1726.

33. Marzot F, Pengo V. Prasugrel for the treatment of patients with acute coronary syndrome. Vasc Health Risk Manag. 2009;5:321-324.

34. Motovska Z, Widimsky P. Improving outcomes in patients undergoing percutaneous coronary intervention: role of prasugrel. Vasc Health Riak Manag. 2009;5:475-481.

35. Norgard NB, Abu-Fadel M. Comparison of prasugrel and clopidogrel in patients with acute coronary syndrome undergoing percutaneous coronary intervention. Vasc Health Riak Manag. 2009;5: 873-882.

36. Silva MA, Donovan JL, Gandhi PJ, et al. Platelet inhibitors in non-ST-segment elevation acute coronary syndromes and percutaneous coronary intervention: glycoprotein IIb/IIIa inhibitors, clopidogrel, or both? Vasc Health Risk Manag. 2006;2:39-48.

37. Tcheng JE, Ellis SG, George BS, et al. Pharmacodynamics of chimeric glycoprotein IIb/IIIa integrin antiplatelet antibody Fab 7E3 in high-risk coronary angioplasty. Circulation. 1994;90:1757-1764.

38. EPIC Investigators. Use of a monoclonal antibody directed against the platelet glycoprotein $\mathrm{IIb} / \mathrm{III}$ a receptor in high-risk coronary angioplasty. $N$ Engl J Med. 1994;330:956-961.

39. EPILOG Investigators. Platelet glycoprotein IIb/IIIa receptor blockade and low-dose heparin during percutaneous coronary revascularization. N Engl J Med. 1997;336:1689-1696. 
40. EPISTENT Investigators. Randomized placebo-controlled and balloon-angioplasty-controlled trial to assess safety of coronary stenting with use of platelet glycoprotein-IIb/IIIa blockade. Lancet. 1998;352(9122):87-92.

41. Topol EJ, Lincoff AM, Kereiakes DJ, et al. Multi-year follow-up of abciximab therapy in three randomized, placebo-controlled trials of percutaneous coronary revascularization. Am J Med. 2002; 113:1-6.

42. Bishara AI, Hagmeyer KO. Acute profound thrombocytopenia following abciximab therapy. Ann Pharmacother. 2000;34:924-930.

43. Barrett JS, Murphy G, Peerlinck K, et al. Pharmacokinetics and pharmacodynamics of MK-383, a selective non-peptide platelet glycoprotein-IIb/IIIa receptor antagonist, in healthy men. Clin Pharmacol Ther. 1994;56:377-388.

44. Platelet Receptor Inhibition in Ischemic Syndrome Management (PRISM) Study Investigators. A comparison of aspirin plus tirofiban with aspirin plus heparin for unstable angina. N Engl J Med. 1998;338: 1498-1505.

45. RESTORE Investigators. Effects of platelet glycoprotein IIb/IIIa blockade with tirofiban on adverse cardiac events in patients with unstable angina or acute myocardial infarction undergoing coronary angioplasty. Circulation. 1997;96:1445-1453.

46. Harrington RA, Kleiman NS, Kottke-Marchant K, et al. Immediate and reversible platelet inhibition after intravenous administration of a peptide glycoprotein IIb/IIIa inhibitor during percutaneous intervention. Am J Cardiol. 1995;76:1222-1227.

47. Tcheng JE, Harrington RA, Kottke-Marchant K, et al. Multicenter, randomized, double-blind, placebo-controlled trial of the platelet integrin glycoprotein IIb/IIIa blocker integrelin in elective coronary intervention. Circulation. 1995;91:2151-2157.

48. PURSUIT Trial Investigators. Inhibition of platelet glycoprotein $\mathrm{IIb} / \mathrm{III}$ a with eptifibatide in patients with acute coronary syndromes. N Engl J Med. 1998;339:436-443.

49. Michelson AD. Methods for the measurement of platelet function. Am J Cardiol. 2009;103 Suppl 3:20A-26A.

50. Christiaens L, Macchi L. Monitoring of the antiplatelet drugs effect in patients with coronary artery disease: what is the real clinical impact? Curr Vasc Pharmacol. 2007;5:293-301.

51. Gibbs NM. Point-of-care assessment of antiplatelet agents in the perioperative period: a review. Anaesth Intensive Care. 2009;37: 354-369.

52. Howard-Alpe GM, de Bono J, Hudsmith L, et al. Coronary artery stents and non-cardiac surgery. Br J Anaesth. 2007;98:560-574.

53. Craft RM, Chavez JJ, Snider CC, et al. Comparison of modified thrombelastograph and Plateletworks whole blood assays to optical platelet aggregation for monitoring reversal of clopidogrel inhibition in elective surgery patients. J Lab Clin Med. 2005;145:309-315.

54. Lennon MJ, Gibbs NM, Weigthman WM, et al. A comparison of Plateletworks ${ }^{\mathrm{TM}}$ and platelet aggregometry for the assessment of aspirin-related platelet dysfunction in cardiac surgical patients. J Cardiothorac Vasc Anesth. 2004;18:136-140.

55. Malinin A, Spergling M, Muhlestein B, et al. Assessing aspirin responsiveness in subjects with multiple risk factors for vascular disease with a rapid platelet function analyzer. Blood Coagul Fibrinolysis. 2004;15:295-301.

56. Roy P, Okabe T, Pinto Slottow TL, et al. Correlates of clinical restenosis following intracoronary implantation of drug-eluting stents. Am J Cardiol. 2007;100:965-969.

57. Stone GW, Moses JW, Ellis SG, et al. Safety and efficacy of sirolimusand paclitaxel-eluting coronary stents. $N$ Eng J Med. 2007;356: 998-1008.

58. Doostzadeh J, Clark LN, Bezenek S, Pierson W, Sood PR, Sudhir K. Recent progress in percutaneous coronary intervention: evolution of the drug-eluting stents, focus on the XIENCE V drug-eluting stent. Coron Artery Dis. 2010;21:46-56.

59. Pinto Slottow TL, Waksman R. Drug-eluting stent safety. Am J Cardiol. 2007;100 Suppl 2:10M-17M.
60. Awata M, Kotani J, Uematsu M, et al. Serial angioscopic evidence of incomplete neointimal coverage after sirolimus-eluting stent implantation: comparison with bare-metal stents. Circulation. 2007; 116:910-916.

61. Spertus JA, Kettelkamp R, Vance C, et al. Prevalence, predictors, and outcomes of premature discontinuation of thienopyridine therapy after drug-eluting stent placement: results from the PREMIER registry. Circulation. 2006;113:2803-2809.

62. King SB, Smith SC, Hirshfeld JW, Jacobs AK, Morrison DA, Williams DO. 2007 Focused Update of the ACC/AHA/SCAI 2005 Guideline Update for Percutaneous Coronary Intervention: a report of the American College of Cardiology/American Heart Association Task Force on Practice Guidelines: 2007 Writing Group to Review New Evidence and Update the ACC/AHA/SCAI 2005 Guideline Update for Percutaneous Coronary Intervention, Writing on Behalf of the 2005 Writing Committee. Circulation. 2008;117:261-295.

63. Cohen M. Antiplatelet therapy in percutaneous coronary intervention: a critical review of the $2007 \mathrm{AH} / \mathrm{ACC} / \mathrm{SCAI}$ guidelines and beyond. Catheter Cardiovasc Interv. 2009;74:579-597.

64. Cuisset T, Frere C, Quilici J, et al. Benefit of a 600-mg loading dose of clopidogrel on platelet reactivity and clinical outcomes in patients with non-ST-segment elevation acute coronary syndrome undergoing coronary stenting. J Am Coll Cardiol. 2006;48:1339-1345.

65. Yong G, Rankin J, Ferguson L, et al. Randomized trial comparing 600- with 300-mg loading dose of clopidogrel in patients with non-ST elevation acute coronary syndrome undergoing percutaneous coronary intervention: results of the Platelet Responsiveness to Aspirin and Clopidogrel and Troponin Increment after Coronary Intervention in Acute Coronary Lesions (PRACTICAL) Trial. Am Heart J. 2009;157:60.e1-60.e9.

66. Mehta SR, Yusuf S, Peters RJ, et al. Effects of pretreatment with clopidogrel and aspirin followed by long-term therapy in patients undergoing percutaneous coronary intervention: the PCI-CURE study. Lancet. 2001;358(9281):527-533.

67. Becker RC, Meade TW, Berger PB, et al. The primary and secondary prevention of coronary artery disease: American College of Chest Physicians Evidence-Based Clinical Practice Guidelines (8th Edition) Chest. 2008;133 Suppl 6:776S-814S.

68. Eisenstein EL, Anstrom KJ, Kong DF, et al. Clopidogrel use and longterm clinical outcomes after drug-eluting stent implantation. JAMA. 2007;297:159-168.

69. Jennings DL, Kalus JS. Addition of cilostazol to aspirin and a thienopyridine for prevention of restenosis after coronary artery stenting: a meta-analysis. J Clin Pharmacol. 2010;50(4):415-421.

70. Albaladejo P, Marret E, Piriou V, Samama CM. Perioperative management of antiplatelet agents in patients with coronary stents: recommendations of a French Task Force. Br J Anaesth. 2006;97:580-582.

71. Douketis JD, Berger PB, Dunn AS, et al. The perioperative management of antithrombotic therapy. Chest. 2008;133:299S-339S.

72. Lecompte T, Hardy JF. Antiplatelet agents and perioperative bleeding. Can J Anesth. 2006;53:S103-S112.

73. Burger W, Chemnitius JM, Kneissl GD, Rücker G. Low-dose aspirin for secondary cardiovascular prevention: cardiovascular risks after its perioperative withdrawal versus bleeding risks with its continuation - review and meta-analysis. J Intern Med. 2005;257:399-414.

74. Helfried M, Florian P, Münch A, et al. Premature discontinuation of antiplatelet drug therapy in cardiovascular risk patients: a preliminary study on the role of P2Y12 receptor monitoring. Eur J Anaesthesiol. 2010;27:138-145.

75. Samama CM, Bastien O, Forestier F, et al; the expert group. Antiplatelet agents in the perioperative period: expert recommendations of the French Society of Anesthesiology and Intensive Care (SFAR) 2001 - summary statement. Can J Anesth. 2002;49:S26-S35.

76. Sabaté S, Mayoral M, Vernetta D, Hernando D, Baxarias P. Intraoperative blood loss and transfusion requirements for radical laparoscopic vs radical retropubic prostatectomy. Eur J Anaesthesiol. 2008;25 Suppl 44:90. 
77. Schouten O, van Domburg RT, Bax JJ, et al. Noncardiac surgery after coronary stenting: early surgery and interruption of antiplatelet therapy are associated with an increase in major adverse cardiac events. $J A m$ Coll Cardiol. 2007;49:122-124.

78. Fox KAA, Mehta SR, Peters R, et al. Benefits and risks of the combination of clopidogrel and aspirin in patients undergoing surgical revascularization for non-ST-elevation acute coronary syndrome: the Clopidogrel in Unstable angina to prevent Recurrent ischemic Events (CURE) Trial. Circulation. 2004;110:1202-1208.

79. Wenaweser P, Rey C, Eberli FR, et al. Stent thrombosis following bare-metal stent implantation: success of emergency percutaneous coronary intervention and predictors of adverse outcome. Eur Heart J. 2005;26:1180-1187.

80. Iakovou I, Schmidt T, Bonizzoni E, et al. Incidence, predictors, and outcomes of thrombosis after successful implantation of drug-eluting stents. JAMA. 2005;293:2126-2130.

81. Balaguer-Malfagón JR, Pomar-Domingo F, Vilar-Herrero JV, Planas-del Viejo AM, Pérez-Fernández E. Trombosis del stent en la era moderna: incidencia, consecuencias y factores predictores (Spanish) Rev Esp Cardiol. 2006;59:842-845.

82. De la Torre-Hernández JM, Alfonso F, Hernández F, et al. Drug-eluting stent thrombosis: results from the multicenter Spanish Registry ESTROFA (Estudio EsSpañol sobre TROmbosis de stents FArmacoactivos). J Am Coll Cardiol. 2008;51:986-990.

83. Caixeta A, Leon MB, Lansky AJ, et al. 5-year clinical outcomes after sirolimus-eluting stent implantation insights from a patient-level pooled analysis of 4 randomized trials comparing sirolimus-eluting stents with bare-metal stents. J Am Coll Cardiol. 2009;54:894-902.

84. Cutlip DE, Windecker S, Mehran R, et al. Clinical end points in coronary stent trials: a case for standardized definitions. Circulation. 2007;115:2344-2351.

85. Camenzind E, Steg PG, Wijns W. Stent thrombosis late after implantation of first-generation drug-eluting stents: a cause for concern. Circulation. 2007;115:1440-1455.

86. Grines CL, Bonow RO, Casey DE, et al. Prevention of premature discontinuation of dual antiplatelet therapy in patients with coronary artery stents. J Am Coll Cardiol. 2007;49:734-739.

87. Carlsson J, James SK, Lindbäck J, et al. Outcome of drug-eluting versus bare-metal stenting used according to on- and off-label criteria. J Am Coll Cardiol. 2009;53:1389-1398.

88. Kirtane AJ, Gupta A, Iyengar S, et al. Safety and efficacy of drug-eluting and bare metal stents: comprehensive meta-analysis of randomized trials and observational studies. Circulation. 2009;119:3198-3206.

89. Lagerqvist B, Carlsson J, Fröbert O, et al. Stent thrombosis in Sweden: a report from the Swedish Coronary Angiography and Angioplasty Registry. Circ Cardiovasc Interv. 2009;2:401-408.

90. Popescu WM. Perioperative management of the patient with a coronary stent. Curr Opin Anaesthesiol. 2010;23:109-115.

91. Baran KW, Lasala JM, Cox DA, et al. A clinical risk score for prediction of stent thrombosis. Am J Cardiol. 2008;102:541-545.

92. van Werkum JW, Heestermans AA, Zomer AC, et al. Predictors of coronary stent thrombosis: the Dutch Stent Thrombosis Registry. J Am Coll Cardiol. 2009;53:1399-1409.
93. Roy P, Bonello L, Torguson R, et al. Temporal relation between clopidogrel cessation and stent thrombosis after drug-eluting stent implantation. Am J Cardiol. 2009;103:801-805.

94. Kimura T, Morimoto T, Nakagawa Y, et al. Antiplatelet therapy and stent thrombosis after sirolimus-eluting stent implantation. Circulation. 2009;119:987-995.

95. Vincenzi MN, Meislitzer T, Heitzinger B, Halaj M, Fleisher LA, Metzler H. Coronary artery stenting and non-cardiac surgery. A prospective outcome study. Br J Anaesth. 2006;96:686-693.

96. Newsome LT, Weller RS, Gerancher JC, Kutcher MA, Royster RL. Coronary artery stents, Part II: Perioperative considerations and management. Anesth Analg. 2008;107:570-590.

97. Sierra P, Tormos P, Unzueta MC, Sabaté M, Monsalve C, Sabaté S. Manejo perioperatorio de la antiagregación en pacientes portadores de stent coronario (Spanish). Rev Esp Anestesiol Reanim. 2008;55 Suppl 1:1-14.

98. Lehot J, Staat P, Ffrench P, Vichova Z, Cannesson M. [Coronary stents and anaesthesia]. Ann Fr Anesth Reanim. 2007;26(9):784-790.

99. King SB, Smith SC, Hirshfeld JW, et al. 2007 focused update of the ACC/AHA/SCAI 2005 guideline update for percutaneous coronary intervention: a report of the American College of Cardiology/American Heart Association Task Force on Practice guidelines. J Am Coll Cardiol. 2008;51:172-209.

100. Poldermans D, Bax JJ, Boersma E, et al. Guidelines for pre-operative cardiac risk assessment and perioperative cardiac management in non-cardiac surgery. Eur Heart J. 2009;30:2769-2812.

101. Broad L, Lee T, Conroy M, et al. Successful management of patients with a drug-eluting coronary stent presenting for elective, non-cardiac surgery. Br J Anaesth. 2007;98:19-22.

102. Bigalke B, Seizer P, Geisler T, Lindemann S, Gawaz M, May AE. Perioperative antiplatelet therapy in patients at risk for coronary stent thrombosis undergoing noncardiac surgery. Clin Res Cardiol. 2009; 98(5):335-339.

103. Eisenberg MJ, Richard PR, Libersan D, Filion KB. Safety of short-term discontinuation of antiplatelet therapy in patients with drug-eluting stents. Circulation. 2009;119:1634-1642.

104. Despotis G, Eby C, Lublin DM. A review of transfusion risks and optimal management of perioperative bleeding with cardiac surgery. Transfusion. 2008;48:2S-30S.

105. Lauritzen B, Tranholm M, Ezban M. rFVIIa and a new enhanced rFVIIa 10analogue, NN1731, reduce bleeding in clopidogrel-treated and in thrombocytopenic rats. J Thromb Haemost. 2009;7: 651-657.

106. Bornemann H, Prüller F, Metzler H. The patient with coronary stents and antiplatelet agents: what to do and how to deal? Eur JAnaesthesiol. 2010;27(5):406-410. doi:10.1097/EJA.0b013e328225b284.

107. Vilahur G, Choi BG, Zafar MU, et al. Normalization of platelet reactivity in clopidogrel-treated subjects. J Thromb Haemost. 2007;5: 82-90.

108. Savonito S, D’Urbano M, Caracciolo M, et al. Urgent surgery in patients with recently implanted coronary drug-eluting stent: a phase II study of "bridging" antiplatelet therapy with tirofiban during temporary withdrawal of clopidogrel. Br J Anaesth. 2010;104(3):285-291.
Vascular Health and Risk Management

\section{Publish your work in this journal}

Vascular Health and Risk Management is an international, peerreviewed journal of therapeutics and risk management, focusing on concise rapid reporting of clinical studies on the processes involved in the maintenance of vascular health; the monitoring, prevention and treatment of vascular disease and its sequelae; and the involvement of

\section{Dovepress}

metabolic disorders, particularly diabetes. This journal is indexed on PubMed Central and MedLine. The manuscript management system is completely online and includes a very quick and fair peer-review system, which is all easy to use. Visit http://www.dovepress.com/ testimonials.php to read real quotes from published authors. 